\title{
OBRAS DE ARTE COMO INTRODUÇÃO AO FILOSOFAR: ARTICULAÇÕES INTERDISCIPLINARES NO ENSINO MÉDIO
}

\author{
WORKS OF ART AS AN INTRODUCTION TO PHILOSOPHY: \\ INTERDISCIPLINARY CONNECTIONS IN HIGH SCHOOL
}

\author{
Thiago Gruner ${ }^{1}$
}

\section{RESUMO}

Este artigo apresenta duas teses sobre as vantagens do uso de obras de arte para o ensino de Filosofia no Ensino Médio: a primeira é a de que obras de arte podem servir de introdução ao filosofar na escola - indo além das questões estéticas e chegando a interrogações da filosofia política, metafísica, moral e epistemológica. Num primeiro momento, apresenta-se exemplos de obras e casos ricos para esse intuito. Num segundo momento, parte desses particulares para uma compreensão mais ampla, explicando, a partir das teses de Arthur Danto, Ronald Moore e Ronai Rocha, o valor didático e filosófico daquelas no Ensino Médio. Ainda quanto à primeira tese, sustenta-se que a arte também serve ao exercício de uma das principais competências filosóficas: a argumentação. A segunda tese é a de que as artes podem servir de ponto de partida para uma proposta curricular interdisciplinar: no presente caso, entre a Filosofia e as demais disciplinas escolares. Apresenta-se possíveis cruzamentos conceituais e temáticos entre as disciplinas em questão, fornecidos por obras de arte e outros fenômenos estéticos. Nossa conclusão é a de que abordar a arte no Ensino Médio, sob o ponto de vista filosófico, é uma oportunidade didática e cognitiva que não deve ser menosprezada.

Palavras-chave: Ensino de filosofia; Filosofia da arte; Ensino médio; BNCC; Interdisciplinaridade.

\section{ABSTRACT}

This paper presents two theses on the benefits of using works of art in Philosophy classes in High School: the first one is that works of art can serve as an introduction to philosophizing in school - going beyond aesthetic issues and raising questions of political, metaphysical, moral and epistemological philosophy. At first, we present examples of works and rich cases for this purpose. In a second moment, we make a move from these particulars towards a broader understanding, explaining, through the theses of Arthur Danto, Ronald Moore and Ronai Rocha, the didactic and philosophical value of Works of art in high school. Still regarding the first thesis, it is maintained that art also suits the purpose of practicing of one of the main philosophical competences: argumentation. The second thesis is that the arts can serve as a starting point for an interdisciplinary syllabus proposal: in the present case, between Philosophy and other school subjects. We introduce possible conceptual and thematic crossings

1 Mestrando em Filosofia pela UFRGS (Cognição e arte). Licenciado em Filosofia pela UFRGS, onde realizou Iniciação Científica em Estética (Nietzsche e Kant). Foi bolsista da CAPES de Residência Pedagógica na Escola Cel. Afonso Emílio Massot. Possui graduação em Produção Audiovisual pela PUCRS (2014) e graduação-sanduíche em Estudos Cinematográficos pela Université Charles de Gaulle - Lille 3 (2013). É professor de Filosofia no Colégio Anchieta e no coletivo Território Popular ambos de Porto Alegre. E-mail: thiagogruner@gmail.com 
Thaumazein, Ano IX, v. 13, n. 25, Santa Maria, p. 75-87, 2020.

between the subjects at issue, provided by works of art and other aesthetic phenomena. Our conclusion is that approaching art in high school, from a philosophical point of view, is a didactic and cognitive opportunity that should not be overlooked.

Keywords: Philosophy teaching. Philosophy of art. High-school. Syllabus. Interdisciplinarity.

\section{INTRODUÇÃO}

O ensino de Humanidades, em especial na educação básica, passa por um momento de intenso questionamento. Autoridades e opinião pública flertam com o ensino das disciplinas consideradas "úteis", apenas, (o que quer que isso signifique) (ORDINE, 2016) e que tragam "retorno de fato e imediato" (JORNAL NACIONAL, 2019). Dado esse contexto, pretendo juntar-me àqueles que têm esforçado-se para provar as qualidades do ensino de Humanidades - que não é nem vago nem inútil, mas dotado de vantagens (NUSSBAUM, 2015). Em especial, esta pesquisa pretende mostrar as potencialidades das Artes e da Filosofia no Ensino Básico - com especial atenção ao Ensino Médio.

Gostaria de defender duas teses neste artigo. A primeira é a de que obras de arte podem servir de introdução ao filosofar na escola. A segunda é a de que as artes podem articular duas ou mais disciplinas: no presente caso, da Filosofia e das demais disciplinas do currículo escolar.

Quanto à primeira tese, pretendo sustentar que colocar a arte em protagonismo, sob a ótica filosófica, tem o mérito de apresentar aos estudantes um pouco de todas as reflexões filosóficas (políticas, epistemológicas, morais etc. - e não apenas estéticas). Minha sustentação passará, num primeiro momento, por apresentar exemplos de obras e casos ricos para esse intuito. Em seguida, passarei desses particulares para uma compreensão mais ampla, explicando, a partir de meu referencial teórico (DANTO, 1986; MOORE, 1998; ROCHA, 2013a) porque obras de arte podem ter valor didático e filosófico no Ensino Médio.

Ainda quanto à primeira tese, pretendo sustentar que a arte também pode servir de introdução ao filosofar na escola se prestarmos atenção na principal das competências filosóficas: a argumentação. De modo que uma aula de filosofia da arte permitiria ao aluno ultrapassar a mera opinião e adentrar o terreno propriamente argumentativo da justificação: dar e pedir razões para a qualidade de uma obra, a interpretação de seu significado etc..

Quanto à segunda tese, gostaria de defender que a arte pode cumprir o papel de articuladora da Filosofia e das demais disciplinas do currículo escolar (como Química, Física, Língua Portuguesa, Literatura, História, Sociologia, Biologia e Matemática - além, é claro, de Artes Visuais e Música). Essa articulação tem sido muito buscada na educação brasileira já há duas décadas², e é o que entende-se por interdisciplinaridade - preconizada mais recentemente pela Base Nacional Comum Curricular (BNCC) (BRASIL, 2018, p. 16). Minha sustentação passará por apresentar possíveis cruzamentos conceituais e temáticos entre as disciplinas em questão, fornecidos por obras de arte e fenômenos estéticos.

Ao final, pretendo ter mostrado que falar de arte, sob o ponto de vista filosófico, é uma oportunidade didática e cognitiva que não encontra paralelo em outras disciplinas. Em suma, esse esforço se justifica na medida em que privar nossos estudantes de fazer filosofia é tirar deles a oportunidade de

2 Vide o parecer 15/98 do Conselho Nacional de Educação (BRASIL, 1998). 
satisfazer "um tipo de curiosidade fundamental, que, pela sua natureza, ocorre parcialmente em qualquer área da experiência humana" (ROCHA, 2013b, [s.p.]) - incluindo a arte.

\section{ARTE E METAFÍSICA}

A metafísica lida com grandes questões filosóficas, como a realidade do tempo e do espaço, a existência do livre-arbítrio, entre outras. A mais geral delas, no entanto, é "o que é o ser?" - que nomeia a subdisciplina conhecida como Ontologia (da palavra grega para "ser").

Não é de hoje que a arte pergunta-se sobre seu próprio ser (aparência ou realidade?). Cópias e fraudes sempre colocaram a questão metafísica e ontológica de saber o que torna uma obra de arte o que ela é. Seria a virtuose do artista ou sua intenção? Seria a experiência do espectador ou o próprio objeto? Essas reflexões ontológicas podem ser direcionadas à arte em geral (à qualquer obra), mas é pelo exemplo de duas, em particular, que pretendo ilustrar a relação entre arte e metafísica.

Em 1936, o fotógrafo estadunidense Walker Evans publicou uma série de fotos sobre os impactos da pobreza americana originada na Crise de 1929. Dentre estas, Alabama tenant farmer wife (fig. 01) mostra o retrato em preto-e-branco de uma mulher de rosto crispado e sério. Décadas depois, em 1981, a artista Sherrie Levine expôs After Walker Evans 4, uma foto grão por grão indistinguível de Alabama tenant farmer wife (fig. 02) (HICK, 2012: p. 48).

Figura 1 - Alabama tenant farmer wife (Impressão sobre papel de gelatina e prata), 1936. 20.9 × 14.4 cm. Walker Evans. Disponível em: https://www.metmuseum.org/toah/works-of-art/2001.415/. Acesso em: 09 jun. 2019.

Figura 2 - After Walker Evans 4 (Impressão sobre papel de gelatina e prata), 1981, 12.8 x 9.8 cm. Sherrie Levine. Disponível em: https://www.metmuseum.org/art/collection/search/267214. Acesso em: 09 jun. 2019.

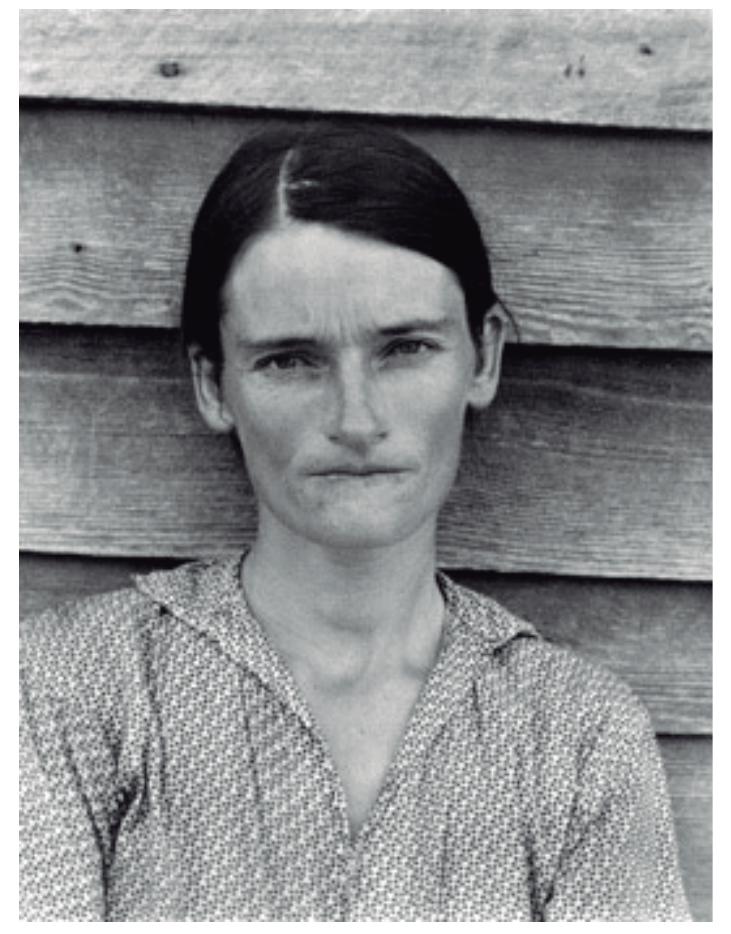

01

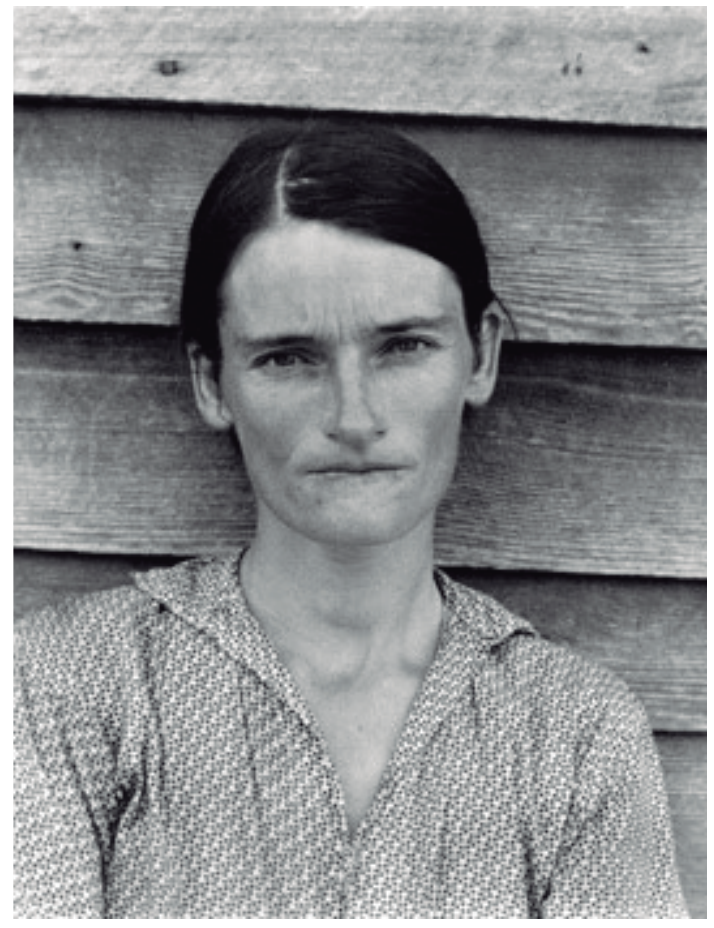

02 
Surge assim a questão que permite aos alunos começarem a filosofar: são ambas a mesma obra? E o que é a obra, em cada caso: apenas a imagem, as reproduções derivadas do negativo original, a ideia de copiar algo...?

Como se não bastasse, em 2001, o artista e programador Michael Mandiberg criou um site (www. aftersherrielevine.com) contendo a (imagem da) obra de Levine, dessa vez reintitulada Untitled, dando nova vida ao ciclo de apropriações. Desnecessário dizer que mais uma rodada de questionamentos filosóficos abrir-se-ia daí.

Em 2011, o rapper Criolo lançou uma canção intitulada Cálice, com a mesma melodia da homônima de Chico Buarque, porém com outra letra. A versão de Criolo contém expressões da periferia paulista e fala do sangue a escorrer entre aqueles que são vítimas da violência urbana e da repressão policial.

A pergunta que poderíamos fazer a um estudante de Ensino Médio é: a canção de Criolo é a mesma que a de Chico Buarque? ${ }^{3}$ Seria uma questão propriamente metafísica, já que questionaria a ontologia de Cálice (e quem sabe de qualquer canção em geral): ela é a sua melodia, letra, autoria todas ou nenhuma?

Se concordássemos que ambas são a mesma música em algum sentido relevante, teríamos de decidir se Cálice de Criolo é uma interpretação inovadora ou um simples plágio. Mas o aluno que encarasse Criolo como um plagiador seria obrigado a rebaixar sua Cálice a uma canção fraudulenta - o que certamente lhe imputaria um grande ônus explicativo. Em Filosofia, uma das virtudes intelectuais é a de não interpretar o interlocutor da pior maneira, mas adotar o chamado princípio de caridade. Segundo Jerrold Levinson (2018: [s.p]), podemos fazer o mesmo perante uma obra de arte: "uma melhor atribuição de intenção a um autor pode envolver, de acordo com um princípio de caridade, a escolha de uma interpretação que torna a obra artisticamente melhor".

Ou seja: evitaríamos ao máximo a interpretação que considerasse Cálice de Criolo um plágio. Um episódio assim seria a situação didática adequada para que os alunos aprendessem a interpretar o significado de uma obra não só da maneira mais correta (epistemicamente falando), mas da maneira que fosse a melhor (esteticamente falando), já que Criolo teria adicionado camadas de riqueza à sua canção quando fez lembrar a original de Chico.

\section{ARTE E FILOSOFIA MORAL}

Uma saída de campo às igrejas barrocas brasileiras certamente impressionaria pelos altares ricamente decorados, o entalhe da madeira nos tetos e paredes. As igrejas do chamado Ciclo do Ouro de Minas Gerais, por exemplo, tem boa parte de sua beleza e sublimidade em função de os menores detalhes serem cobertos de ouro.

Mas o que diriam os alunos se soubessem que essas igrejas foram construídas na base do trabalho escravo, por um regime injusto? A beleza das obras diminuiria? Deveríamos deixar de visitar e apreciar as igrejas do Barroco porque construídas com mão de obra escrava? Deveríamos deixar de assistir à série House of cards e prestigiar o trabalho de Kevin Spacey depois de sabermos que o ator foi um predador sexual? Questionamentos desse tipo nos levam a perguntar se a arte está livre de

3 Agradecimentos à professora Gisele Secco pelo fecundo exemplo. 
considerações morais (isto é: se a arte está isenta de ser julgada por critérios do que é o bem e o mal, o certo e o errado, o desejável e o condenável).

Kant (1790/2016) diria que sim. Que o que é próprio da avaliação estética é o seu desinteresse por questões fáticas da obra (quem a produziu, com que materiais, em que contexto e porquê), importando apenas o sentimento que a obra provoca naqueles que a viram ou ouviram. Essa posição foi mais tarde resumida pelo lema "arte pela arte" - arte livre de moralismos e propósito prático; arte que apenas emociona e sensibiliza.

No entanto, experiências da vida real mostram que o senso comum diverge de Kant e que a arte presta contas, sim, aos costumes. O exemplo conhecido mais recente é o do fechamento forçado da exposição Queermuseum, em Porto Alegre, que continha obras com representações de sexo interracial e zoofílico (caso de Cena de interior II) ou com representações de hóstias marcadas em sangue cênico com palavras como "vulva", "língua" e "buceta" (Et verbum), e que por isso foram consideradas como repugnantes e até criminosas. A mera representação (imagem da coisa), nesses casos, foi suficiente para chocar o gosto local de alguns.

E o que diríamos de casos extremos, como a performance encenada no filme The Square ${ }^{4}$ ? Seria ela moralmente aceitável, apesar de sua violência e agressividade?

Uma atividade em sala de aula poderia contrapor o entendimento daqueles que se ergueram contra a Queermuseu, por exemplo, ao do escritor francês Stendhal, para quem o trabalho do artista é como carregar um espelho, sem poder deixar de mostrar a realidade de uma estrada em condições ruins; mas que, pela imagem do espelho, é equivocadamente acusado de ser aquele que deixou a estrada em tais condições, em vez de ser aquele que apenas a retratou.

Um meio termo entre as duas posições citadas acima seria o de responsabilizar o artista, mas jamais a obra (prenda-se ou multe-se o autor, mas jamais censure-se a obra).

Casos como esses são a oportunidade para que, através da arte, alunos e alunas compreendam e apliquem conceitos morais como responsabilidade, bem, valor, intenção e consequência.

\section{ARTE E FILOSOFIA POLÍTICA}

Pensar se a arte pode cumprir um propósito político é pensar mais uma vez o desinteresse kantiano e o lema da arte pela arte. Propaganda estatal na forma de cinema, monumentos ou canções, por exemplo, é arte? Quando passa a cumprir o papel de conscientizar as massas ou de desenvolver virtudes cívicas entre os cidadãos, que relevância têm as qualidades estéticas de uma obra?

Ademais, a filosofia política, desde Platão e Aristóteles, procura responder a o que é a justiça e o que é um Estado ideal (justo e em que gostaríamos de viver). Esses questionamentos são automaticamente levantados quando pensamos no caso da célebre Lei Rouanet (BRASIL, 1991): é justo que o Estado financie as artes e a cultura? $\mathrm{O}$ financiamento deve estar restrito ao retorno econômico ou deve contemplar apenas o mérito estético e artístico? Ele deve contemplar o gosto de todos os cidadãos ou deve escolher um conjunto de valores a serem incentivados - em detrimento dos projetos de vida pessoais de alguns dos cidadãos?

4 Ficção (152min), direção de Ruben Östlund, 2018.

5 Ainda que indiretamente, visto que se trata de um incentivo por renúncia fiscal. 
Provocar os alunos de Ensino Médio a responder a essas questões é uma oportunidade de apresentar os principais conceitos da área (interesse público e interesse privado, liberdade etc.), bem como suas principais teorias (liberalismo, comunitarismo, republicanismo etc.).

\section{ARTE E EPISTEMOLOGIA}

A epistemologia nasce de dois questionamentos: "o que é conhecimento - e como ele é adquirido?". Assim, uma aula de filosofia da arte poderia perguntar se a arte traz conhecimento.

Já Platão, na República, havia proposto uma resposta: a arte é aparência das aparências, é um simulacro de péssima qualidade. Ela apela para a parte não-racional da alma e engana - porque apenas imita, em vez de mostrar a realidade tal qual ela é.

Para filósofos mais recentes, como Noël Carroll (apud HICK, 2015: p. 165), no entanto, a arte pode sim trazer conhecimento (porque pela ficção investiga-se a vida em suas possibilidades).

Os melhores exemplos, creio, seriam dados pelos próprios alunos: o que eles aprendem com as novelas, músicas, graphic novels, filmes e vídeos que consomem? Testam em seus relacionamentos lições tiradas de seus personagens preferidos? Se considerarmos que um filme como Matrix é um experimento mental acerca da (ir)realidade do mundo, que conclusões tiraríamos dele? É na adolescência, justamente, que o pensamento torna-se capaz de operar de modo hipotético-dedutivo (PIAGET, 1972), assumindo temporariamente a verdade de uma proposição para daí tirar conclusões. E isso, em um sentido, já é descobrir algo - se não sobre como o mundo é, pelo menos sobre como ele poderia ser.

Esse movimento pode ser especialmente oportuno junto ao público mais jovem, que pode considerar o conhecimento como sendo apenas aquele derivado dos laboratórios científicos - e não da experiência artística.

Por fim, se tal tese parecer forte, há outros filósofos que localizam o valor cognitivo da arte na oportunidade única de uma experiência que pode exercitar nossas faculdades cognitivas (como a sensoriomotricidade, a imaginação, a conceituação etc.) (NOË, 2015).

\section{ARTE E ARGUMENTAÇÃO}

A arte também pode ajudar na introdução ao filosofar na escola se prestarmos atenção na principal das competências filosóficas: a argumentação (COSTA, 2003). Nesse sentido, uma aula de filosofia da arte permitiria ao aluno ultrapassar a mera opinião sobre uma manifestação artística (o que o senso comum entende quando diz que "gosto é gosto e não se discute") e adentrar o terreno propriamente argumentativo da justificação: dar e pedir razões para a qualidade de uma obra, a interpretação de seu significado etc.:

Aesthetic experience happens only where there is the possibility of substantive disagreement, and so also the need for justification, explanation and persuasion. The work of art is only experienced when it is experienced as making claims on us, claims we need to adjudicate. (NOË, 2012, p. 126) 
Momentos assim seriam a oportunidade de exercitar a análise e composição de argumentos uma vez suposto que discutir sobre arte já seja algo natural, uma atividade que gostamos de fazer (ao sair do cinema, explicando porque o filme não nos agradou; ao tentarmos eleger o melhor álbum de uma banda, e porquê; ao elencarmos o personagem mais interessante de uma série etc..). Alunos de ensino médio não seriam exceção a essa regra.

Ato contínuo, revelar-se-ia a própria controvérsia filosófica de se é possível convencer alguém da beleza de uma obra. Kant (1790/2016) não só distingue juízos lógicos de juízos estéticos, como considera a empreitada argumentativa fadada ao fracasso, ainda que haja algo do juízo estético que sugira uma "comunicação universal" (§ 143) - isto é: que para julgar algo belo, o sujeito deva considerar seu sentimento de prazer como sendo universalizável, ainda que ele de fato não o seja.

O limite que os sentimentos estéticos encontram na lógica da discursividade são, aliás, um mote para uma proposta interdisciplinar com Língua Portuguesa e Literatura, como pretendo mostrar mais adiante.

\section{DO VALOR FILOSÓFICO E DIDÁTICO DAS OBRAS DE ARTE}

Até aqui pretendi mostrar como fazer filosofia sobre a arte permite não só pensar as questões próprias do campo artístico e estético (o que é arte, o que é o belo etc.), mas também permite fazer filosofia moral, política, metafísica e epistemológica. Fiz isso através de alguns exemplos, mas segundo Arthur Danto (1986), há algo na arte, em geral, que a faz ser inerentemente problemática - e que por isso chama nosso questionamento. A arte, sobretudo a contemporânea, ao tornar-se cada vez mais conceitual, aproximou-se, ela mesma, de uma prática filosófica.

Cabe ao professor aproveitar-se dessa feliz coincidência para usar obras como as mencionadas a favor de uma reflexão filosófica em sala de aula. É a proposta de Ronald Moore (1998) com seu "método de caso" (case method approach), para quem são ao menos quatro as vantagens do uso de obras de arte para o filosofar:

primeiro, os alunos são estimulados a confrontarem, por conta própria, os grandes problemas estéticos; segundo, casos estéticos [aesthetic cases] chamam a atenção de estudantes como quebra-cabeças intelectuais cujas soluções recaem sobre os contextos práticos da arte e do juízo estético; terceiro, ao tentarem resolver esses quebra-cabeças, estudantes frequentemente são levados a expressarem linhas de pensamento muito além dos presentes casos e a apreciarem argumentações diferentes que podem ser relevantes para os casos em questão; e quarto, alunos a quem são apresentados vários casos estéticos, ou uma série de variações dos fatos de um dado caso, podem perceber, por si mesmos, o contínuo drama de conflito e desenvolvimento que caracteriza esse campo. (MOORE, 1998, p. 100-101, minha tradução)

Quando os problemas filosóficos são identificados no mundo vivido "como uma "situação de caráter concreto" (ASTOLFI et al., 1997 apud PERRENOUD, 2000, itálicos do original) (e seguindo Danto podemos considerar obras de arte como problemas filosóficos concretos), eles servem de ponto de partida de uma reflexão que "permita efetivamente ao aluno formular hipóteses e conjecturas" (idem). São aquilo que, por não ter resposta fácil ou pronta, motiva os alunos a continuarem a pensar: 
Thaumazein, Ano IX, v. 13, n. 25, Santa Maria, p. 75-87, 2020.

Exemplos exóticos bem escolhidos, ou mesmo inventados, conseguem abalar as convicções pré-reflexivas dos estudantes tirando-os dos contextos conhecidos em que os palpites do senso comum são geralmente confiáveis. Esse deslocamento é, sobretudo, mais importante para entender a arte do que qualquer outra coisa. (MOORE, 1998, p. 101, minha tradução)

Sabendo bem escolher as obras de arte em questão, aproximando o mundo da arte do mundo vivido do aluno e ao mesmo tempo fazendo-o estranhá-lo, o professor poderá apresentar a situação-problema (uma obra de arte) e a ferramenta de investigação e resolução dela (a atividade filosófica). É o que Ronai Rocha considera ser a própria didática (uma "arte da graça”):

\begin{abstract}
A graça de uma aula de filosofia reside, em parte, nessa capacidade didática de realizar a imersão na cotidianidade de forma combinada com estratégias de estranhamento. Nada mais familiar para nós do que o cotidiano e nada mais difícil do que produzir um distanciamento reflexivo dele. Uma estratégia poderosa para uma didática da filosofia é fazer com que o olhar do aluno transite dos temas para os processos de argumentação e análise e para prática de exercícios de imaginação projetiva. (ROCHA, 2013a, p. 25)
\end{abstract}

E é por isso que de uma filosofia da arte na escola não se exclui nenhum objeto de reflexão, em especial aqueles próximos da vida do aluno: por que não fazer uma filosofia do carnaval e do cinema? Ou sobre o batuque dos terreiros e o canto neopentecostal? Sobre as capacidades terapêuticas da $\operatorname{arte}^{6}$ (que os alunos provavelmente devem sentir) ou sobre o ethos veiculado nas letras do funk? Esses e outros caminhos abrem-se para o trabalho em sala de aula como pretendo mostrar melhor, na sequência.

\title{
A ARTE COMO PONTO DE ENCONTRO INTERDISCIPLINAR ENTRE A FILOSOFIA E AS DEMAIS DISCIPLINAS DO CURRÍCULO ESCOLAR
}

De agora em diante pretendo mostrar como a arte também pode ser o rico ponto de encontro que realize a tão buscada interdisciplinaridade no currículo escolar. As relações interdisciplinares que apontarei se dão entre a Filosofia e as demais disciplinas. Trata-se menos de uma tese robusta, e mais de uma sugestão de trabalho a ser desenvolvida - e executada se possível, é claro.

Algumas das relações interdisciplinares levantadas se dão entre afinidades temáticas, problemáticas ou conceituais (ROCHA, 2013a: p. 26). Seja porque um mesmo conceito é utilizado ambiguamente entre duas ou mais disciplinas ("lei" em Física, Sociologia e História, digamos), seja porque toda disciplina e atividade escolar comporta um aspecto reflexivo (id., ibid.). Outras relações foram encontradas no cruzamento dos respectivos objetos de interesse (formas geométricas, no caso de Estética (Filosofia) e Matemática, por exemplo).

6 Sugeridas desde Platão, no séc. V a.C., até Alain de Botton, na nossa década do século XXI. 


\section{ARTE E FILOSOFIA COM QUÍMICA E FÍSICA}

A elaboração e teste de hipóteses, bem como a interpretação de dados e indícios é o que constitui em grande parte o método científico - no caso da escola, muito próprio à Física e à Química. Gostaria de sugerir que os conceitos de evidência, interpretação e hipótese podem ser tematizados pela aula de filosofia da arte: o que há de comum em interpretar dados de um equipamento e interpretar uma partitura? As evidências sobre o significado de uma obra são do mesmo tipo que as encontradas na natureza? E as hipóteses: guardam semelhanças?

Todos que já terminaram de assistir a uma série perguntando-se o que o último episódio quis dizer, ou que, ao visitarem um museu, questionaram-se sobre o que o artista "quis passar", quiseram descobrir, na verdade, o significado da obra de arte - pressupondo às vezes, inclusive, uma determinada intenção do artista.

São várias as teorias filosóficas que buscam identificar o que determina o significado de uma obra de arte. Uma delas é o intencionalismo hipotético, seguindo Levinson (como já visto), que recomenda elaborarmos hipóteses acerca do significado da obra que, i) sejam epistemicamente as melhores ("que tem a maior probabilidade de ser correta, dada a totalidade dos indícios disponíveis a quem está na posição de espectador ideal" (LEVINSON, 2018); e que ii) sejam artisticamente as melhores, isto é: que, ceteris paribus, tornem a obra mais rica.

Na hora de interpretar o significado de Cálice de Criolo, por exemplo, um "espectador ideal" saberia que um dos indícios disponíveis é a existência de uma música anterior também intitulada Cálice - a quem Criolo muito provavelmente faz referência, já que também compartilham a mesma melodia. O contexto, aqui, inescapavelmente força uma interpretação do significado da obra para além daquilo identificado apenas "dentro" da obra.

E nas ciências da natureza: há margem para interpretarmos evidências à luz do contexto? Será que os alunos conseguiriam inventar um "método científico" de interpretação do significado de obras de arte? Responder a essa questão passa, creio, por ter clareza dos conceitos já mencionados.

\section{ARTE E FILOSOFIA COM LITERATURA E LIINGUA PORTUGUESA}

A Filosofia pode perguntar pelos limites do discurso oral e escrito na hora de expressarmos os sentimentos estéticos: a linguagem dá conta de expressar o que sentimos quando ouvimos uma música, por exemplo?

Essa seria a oportunidade de apresentar aos alunos a diferença entre os conceitos de denotação e conotação, entre os discursos descritivos (científico, jornalísticos etc.) e poéticos etc..; e de perguntar a eles se sentem-se convencidos pelos pares quando tentam argumentar a favor ou contra a qualidade de uma obra de arte. 


\section{ARTE E FILOSOFIA COM HISTÓRIA E SOCIOLOGIA}

Em 2016 um adolescente resolveu deixar seus óculos no chão do Museu de Arte Moderna de São Francisco para saber se as pessoas encarariam o objeto como uma obra de arte. A ideia deu certo: os adolescentes twittaram fotos mostrando os visitantes contemplando e fotografando os óculos no chão (THE GUARDIAN, 2018).

Disso, por si só, já poderíamos perguntar: os óculos eram uma obra de arte? Muitos estariam dispostos a dizer que não, visto que os adolescentes não eram artistas. Ocorre que no dia seguinte o museu retwittou o post dos adolescentes, perguntando "teríamos um Marcel Duchamp em nosso meio?".

Para os que defendem a teoria institucional da arte, neste momento os óculos eram sérios candidatos a tornarem-se obra de arte. Os institucionalistas dizem que não há uma definição estanque de arte, e que na verdade são aqueles que participam do chamado "mundo da arte" (curadores, público, críticos, teóricos etc.) que ditam o que é e o que não é arte (HICK, 2012: p. 35).

Esta seria a oportunidade de estudar, junto à disciplina de Sociologia, se não estamos a falar de uma definição de arte de classe, isto é: ditada por uma elite cultural dominante, com acesso aos meios financeiros, de informação e opinião - de modo que a (definição de) arte seria inteiramente submissa aos arranjos sociais.

Entra a disciplina de História. A ideia dos adolescentes teria sido possível antes de 2016 - e a de Duchamp, antes de 1917? Não para o filósofo Arthur Danto (1986), para quem cada obra e definição de arte tem um tempo e um espaço para surgirem (nem antes, nem depois) - um certo zeitgeist, que pode ser entendido nas suas causas e consequências junto ao professor de História.

Também em Sociologia seria possível identificar, junto aos alunos, qual é a estética da periferia (isto é: dos excluídos geográfica, cultural, economicamente etc.). Aqui apareceriam como resposta as pichações, por exemplo (são arte?). Em radical oposição a essa exclusão indesejada, o professor poderia apresentar aos alunos a inclusão forçada do totalitarismo pela uniformização estética (símbolos, vestuário, cores etc.). Junto do professor de História, esse seria o momento de apresentar aos alunos a filosofia da arte dos movimentos totalitários do século XX - o nazismo como resgate do classicismo supostamente ariano; o realismo soviético como uma rejeição à subjetividade supostamente burguesa.

\section{ARTE E FILOSOFIA COM ARTES VISUAIS E MÚSICA}

Junto às disciplinas de artes (Artes Plásticas e visuais, Música e Teatro) as questões filosóficas abordáveis são aquelas mais tradicionais no próprio campo da Estética e da Filosofia da Arte: o que é arte? Existe jeito certo de apreciar uma obra de arte? A beleza que há na natureza é a mesma da arte? E o que é a beleza (e o feio, o monstruoso, o sublime etc.)? A música é como uma linguagem - ela comunica?

7 Artista francês da primeira metade do século XX, inventor dos ready-mades; autor de A fonte (1917), obra particularmente célebre, consistindo em um urinol comprado pronto e assinado. 


\section{ARTE E FILOSOFIA COM BIOLOGIA E MATEMÁTICA}

As ilustrações de Ernst Haeckel (biólogo e zoólogo do século XIX) de espécies de ascídias, líquen e algas confundem-se com obras de arte geométricas (fig. 03). Há algo nelas de belo e fascinante que certamente faria os alunos perguntarem-se: a beleza está mesmo nos olhos de quem vê ou ela pertence ao objeto?

Figura 3 - Diatomáceas (Diatomea) (prancha 4) (Litografia), 1904. Ernst Haeckel.

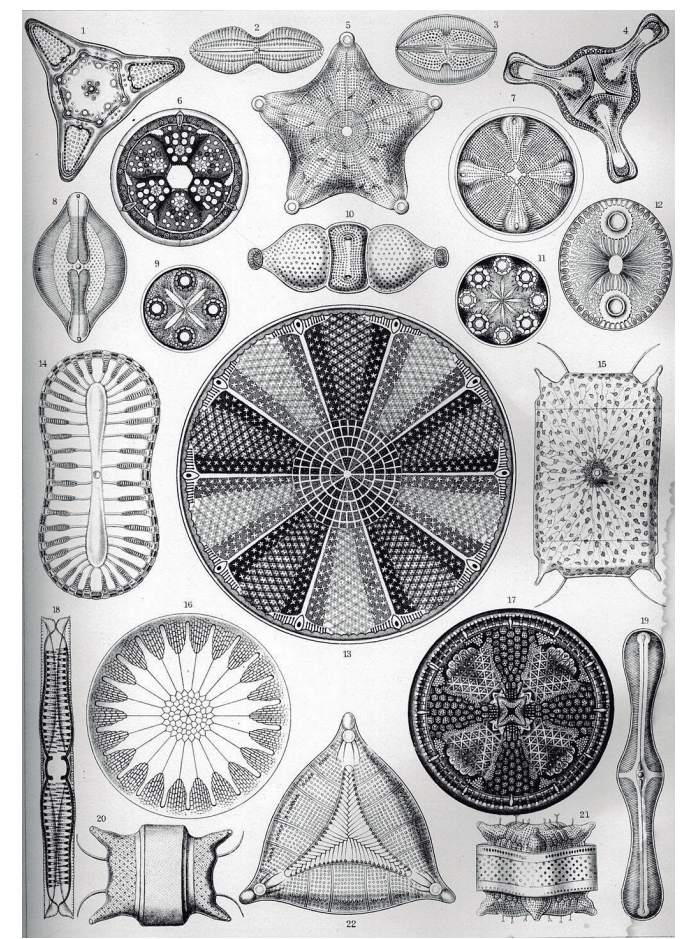

Fonte: Disponível em: https://commons.wikimedia.org/wiki/File:Haeckel_Diatomea_4.jpg. Acesso em: 09 jun. 2019.

É conhecida a presença (aproximada) da proporção dourada (a divisão de um n-ésimo termo da sequência de Fibonacci pelo termo anterior, cujo resultado é o número phi) em formas da natureza como plantas e até o corpo humano. Essa proporção já tivera sido utilizada na Grécia Antiga, foi retomada pelos renascentistas e ainda hoje é utilizada no design gráfico como propriedade objetiva de beleza.

Independentemente da proporção dourada, todo outro tipo de proporção e ordenamento geométricos são amplamente exploradas como veículos de beleza. É o caso dos famosos arabescos e da arte islâmica, de modo geral, e também das rosáceas coloridas em vitrais góticos. Concordariam os alunos que a beleza está nessas qualidades? Se sim, então por que sustentar que "gosto não se discute"?

Junto dos professores de Matemática e Biologia, essas seriam possíveis oportunidades de uma atividade prática em Geometria e Botânica, respectivamente. 


\section{CONSIDERAÇÕES FINAIS}

Procurei defender, a partir de Ronald Moore, Arthur Danto e Ronai Rocha, que o uso de obras de arte pode ter grande valor didático e filosófico. Além das questões tradicionais próprias aos campos da Estética e da Filosofia da Arte, o uso de obras de arte também pode introduzir um estudante de Ensino Médio (que tem contato, em seu cotidiano, com diversas manifestações artísticas) às demais reflexões filosóficas tradicionais (metafísicas, morais, políticas e epistemológicas). E isso, conforme António Costa, sem perder de vista a principal das competências filosóficas: a argumentação. Minha sustentação, seguindo Moore e seu "método de caso", passou por apresentar exemplos de obras reais que cumpririam essa tarefa.

Também busquei defender, ainda a partir de Ronai Rocha, a tese de que obras de arte podem servir de articuladoras interdisciplinares entre a Filosofia e os demais componentes curriculares da escola. Em resumo, essa articulação se dá seja porque um conceito é utilizado ambiguamente entre duas ou mais disciplinas (cabendo à Filosofia fazer o exame desse conceito), seja porque há objetos de interesse (fenômenos artísticos e estéticos) comuns à mais de uma disciplina.

Em suma, minha intenção foi mostrar que, apesar dos atuais questionamentos ao ensino de Humanidades, as Artes e a Filosofia tem grande potencial formativo no Ensino Básico - sobretudo no Ensino Médio.

\section{REFERÊNCIAS}

BRASIL. Guiomar Namo de Mello. Conselho Nacional de Educação - Câmara de Educação Básica. Parecer $\mathbf{n}^{\mathbf{0}}$ CEB 15/98. [S.I.]: MEC/CNE, 1998.

. Lei no 8313, de 23 de dezembro de 1991. Brasília, DF, 1991.

. Ministério da Educação. Base nacional comum curricular: 4ª versão. Brasília, DF, 2018.

COSTA, António Paulo. A avaliação em filosofia. In: MURCHO, Desidério (Org.). Renovar o ensino de filosofia. Lisboa: Gradiva, 2003. p. 69-87.

DANTO, Arthur. The philosophical disenfranchisement of art. New York: Columbia University Press, 1986.

HICK, Darren Hudson. Introducing aesthetics and the philosophy of art. New York: Continuum, 2012.

JORNAL NACIONAL. MEC estuda corte de investimentos nas faculdades de ciências humanas. 2019. Disponível em: https://glo.bo/3mgycG5. Acesso em: 12 jun. 2019.

KANT, Immanuel. Crítica da faculdade do juízo. Rio de Janeiro: Forense Universitária, 2016, 3a. ed.

LEVINSON, Jerrold. Intenção e interpretação na literatura. Tradução de Vitor Guerreiro. [S.I.]: Crítica na rede, 2018. Disponível em: https://criticanarede.com/est_qdarte.html.

NOË, Alva. Strange tools: Art and human nature. New York: Hill And Wang, 2015.

. Varieties of presence. Cambridge, Massachusetts: Harvard University Press, 2012. 
MOORE, Ronald. The case method approach to the teaching of aesthetics. In: KASACHKOFF, Tziporah. Teaching philosophy. Lanham, Maryland: Rowman \& Littlefield, 1998. p. 98-110.

NUSSBAUM, Martha. Sem fins lucrativos: porque a democracia precisa das humanidades. São Paulo: WMF Martins Fontes, 2015.

ORDINE, Nuccio. A utilidade do inútil. Rio de Janeiro: Zahar, 2016.

THE GUARDIAN. Pair of glasses left on US gallery flor mistaken for art. Disponível em: https://bit.ly/2Tkgs03. Acesso em: 09 dez. 2018.

PERRENOUD, Philippe. Dez novas competências para ensinar. Tradução de Patrícia Ramos. Porto Alegre: Artes Médicas Sul, 2000.

PIAGET, Jean. Intellectual evolution from adolescence to adulthood. Human development, v. 15, p. 1-12, 1972.

ROCHA, Ronai. O lugar da filosofia no currículo escolar. In: SPINELLI, Priscilla [et al.] (Org.). Diálogos com a escola: experiências em formação continuada em filosofia na UFRGS, v. 1. Porto Alegre: Evangraf, 2013a. p. 17-28.

. Onze teses sobre Filosofia e Interdisciplinaridade. 2013b. Disponível em: https://bit.ly/34mboP2. Acesso em: 09 jun. 2019. 
